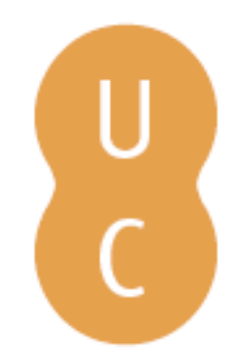

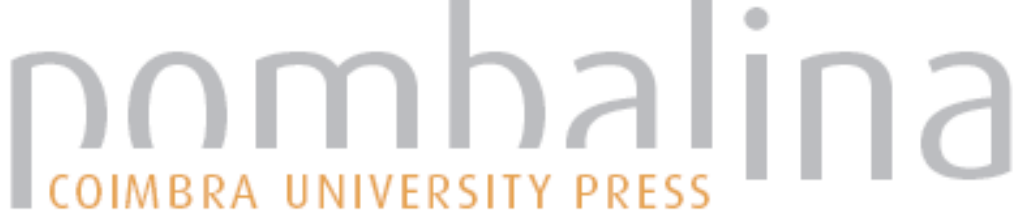

\section{Conservação e restauro fluvial}

Autor(es): $\quad$ Cortes, Rui; Ferreira, Teresa; Hughes, Samantha Jane

Publicado por: Imprensa da Universidade de Coimbra

URL

persistente: URI:http://hdl.handle.net/10316.2/45892

DOI: $\quad$ DOI:https://doi.org/10.14195/978-989-26-1624-7_15

Accessed : $\quad$ 26-Apr-2023 14:01:51

A navegação consulta e descarregamento dos títulos inseridos nas Bibliotecas Digitais UC Digitalis, UC Pombalina e UC Impactum, pressupõem a aceitação plena e sem reservas dos Termos e Condições de Uso destas Bibliotecas Digitais, disponíveis em https://digitalis.uc.pt/pt-pt/termos.

Conforme exposto nos referidos Termos e Condições de Uso, o descarregamento de títulos de acesso restrito requer uma licença válida de autorização devendo o utilizador aceder ao(s) documento(s) a partir de um endereço de IP da instituição detentora da supramencionada licença.

Ao utilizador é apenas permitido o descarregamento para uso pessoal, pelo que o emprego do(s) título(s) descarregado(s) para outro fim, designadamente comercial, carece de autorização do respetivo autor ou editor da obra.

Na medida em que todas as obras da UC Digitalis se encontram protegidas pelo Código do Direito de Autor e Direitos Conexos e demais legislação aplicável, toda a cópia, parcial ou total, deste documento, nos casos em que é legalmente admitida, deverá conter ou fazer-se acompanhar por este aviso.

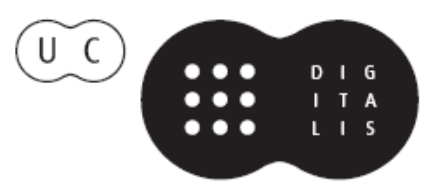


MARIA JOÃO FEIO

VERÓNICA FERREIRA

(EDS.)

\section{IMPRENSA DA \\ UNIVERSIDADE \\ DE COIMBRA \\ COIMBRA \\ UNIVERSITY \\ PRESS}

\section{RIOS DE PORTUGAL COMUNIDADES, PROCESSOS E ALTERAÇÕES}




\section{CA P ÍT UL O 15 \\ CON S E R VAÇ ÃO E \\ RESTAURO FLUVIAL}

Rui Cortes $^{1}$, Teresa Ferreira ${ }^{2}$ \& Samantha Jane Hughes ${ }^{3}$

${ }^{1}$ Centro de Investigação e de Tecnologias Agroambientais e Biológicas, Universidade de Trás-os-Montes e Alto Douro, Portugal, rcortes@utad.pt

${ }^{2}$ Instituto Superior de Agronomia, Universidade de Lisboa, Portugal, terferreira@ isa.utl.pt

${ }^{3}$ Centro de Investigação e de Tecnologias Agroambientais e Biológicas, Universidade de Trás-os-Montes e Alto Douro, Portugal, shughes@utad.pt

Resumo: A ciência de restauro fluvial já faz parte do paradigma da gestão integrada dos recursos hídricos. O processo de restauro fluvial é holístico, dinâmico e colaborativo com o fim de diminuir os impactos e reintroduzir processos naturais que garantam o provisionamento sustentável de serviços de ecossistema. Ações eficazes e sustentáveis de restauro fluvial requerem uma abordagem multidisciplinar e a participação social no que respeita às atividades de uso do rio, da água e do território. Um projeto de restauro bem sucedido deve obedecer a vários objetivos fundamentais, tais como a realização de estudos de caracterização, a implementação de medidas de restauro que garantam a melhoria do ecossistema fluvial, garantir que os impactos negativos associados às ações de restauro sejam temporários e a implementação de programas de monitorização para 
avaliar a evolução das intervenções. Neste capítulo descrevemos aspetos e considerações fundamentais do processo de restauro fluvial.

Palavras-chave: engenharia natural, infraestruturas verdes, monitorização, requalificação, restauro

\section{Necessidade de restauração fluvial}

"Um rio saudável e autossustentável fornecerá bens e serviços ecológicos e sociais importantes dos quais a vida humana depende..." 1 . O estado profundamente alterado e degradado dos rios em quase todo o planeta resulta da atividade humana ao longo de muitos séculos; em especial desde a revolução industrial. A perda de serviços de ecossistema (p.ex., alimento, água potável, regulação de erosão e da qualidade da água, formação do solo, a manutenção do ciclo hidrológico e biodiversidade) associada com a degradação do meio fluvial influencia, de forma negativa, o bem-estar humano. O crescente investimento e nível de conhecimento em técnicas de restauro ou de reabilitação fluvial tem sido um grande impulsionador na recuperação de serviços de ecossistema fluvial e do seu estado ecológico.

Conservação, reabilitação e restauro do meio fluvial são conceitos que frequentemente se cruzam e cujo significado nem sempre é consensual. A conservação refere-se à manutenção de características ecológicas que permitam melhorar habitats e ecossistemas naturais de elevado valor e apoiar a biodiversidade. A reabilitação refere-se ao retorno de algumas funções e estruturas do ecossistema natural que se afastaram profundamente do estado original. Em último lugar, o restauro refere-se à condução do ecossistema degradado, por redução das pressões e intervenções 
estruturais, para uma situação semelhante àquela que encontraríamos sem interferência humana, através da recuperação de processos e funções naturais.

O restauro ecológico envolve mudanças estruturais do ecossistema, para as quais é necessário alterar a morfologia, a hidrologia e o estado químico, daí resultando respostas biológicas, de forma a recuperarem-se os ecossistemas e maximizarem-se os benefícios para a sociedade. As medidas de restauro implementadas no rio e na sua bacia de drenagem obrigam, necessariamente, ao esforço e participação da sociedade humana no seu todo, exigindo a conciliação das diferentes atividades entre si e com as necessidades dos ecossistemas. Geralmente, esta conciliação é objeto de planeamento e participação ativa, no caso do espaço europeu, através dos Planos de Gestão de Bacia Hidrográfica. A participação social, no que respeita às atividades de uso do rio, da água e do território, é essencial no desenvolvimento de uma ação de restauro fluvial eficaz e sustentável.

O conceito do restauro - uma resposta holística e participativa contra a degradação dos sistemas fluviais - é relativamente recen$\mathrm{te}^{2,3}$. A evolução da "ciência" multidisciplinar de restauro fluvial tem sido notável ao longo das últimas 3 décadas, consequência da implementação de medidas legislativas europeias tais como a Diretiva Habitats ${ }^{4}$, a Diretiva Quadro da Água (DQA) ${ }^{5}$ e a Diretiva Relativa à Avaliação e Gestão dos Riscos de Inundações ${ }^{6}$, bem como o desenvolvimento de projetos europeus que reconhecem os múltiplos benefícios de uma abordagem socio-ecológica na utilização de infraestruturas verdes e azuis (p.ex., Medidas Naturais de Retenção de Água e a Estratégia da UE sobre Infraestruturas Verdes). Além destas abordagens mais pragmáticas, a consciência crescente dos benefícios para a coesão social e a saúde pública através do contato humano com a natureza é mais uma vertente importante a considerar na área de restauro dos ecossistemas degradados ${ }^{7,8}$. 


\section{Restauro ecológico e socio-ecologia}

O restauro fluvial é um processo inteiramente socio-ecológico. Baseia-se na participação ativa de stakeholders para a melhoria de sistemas degradados, do aprovisionamento dos serviços de ecossistema e do bem-estar humano. Exemplos europeus de abordagens socio-ecológicas incluem a Rede Natura 2000, estabelecida no âmbito da Diretiva Habitats e os Planos da Gestão das Regiões Hidrográficas (PGRH) da DQA. Em ambos os casos, a atividade humana é regulamentada ou balizada e são realizados esforços no sentido da diminuição de pressões e da recuperação de valores naturais. No caso da DQA, estão também associados mecanismos de operacionalização do restauro ecológico através de Programas de Medidas.

Todavia, as vertentes sociais e ecológicas de uma ação de restauro podem ter uma ênfase diferente, dependendo dos seus objetivos principais 9 . O enfoque de ações de restauro de índole conservacionista vira-se para as espécies e habitats alvo. Noutros casos, uma abordagem de restauro de processos e funções dos ecossistemas é focada em objetivos ambientais que garantam o bom funcionamento do ecossistema, assim beneficiando as atividades humanas (p.ex., a implementação de Programas de Medidas para atingir o "Bom estado" ecológico no âmbito dos PGRH da DQA ou medidas para diminuir o risco de episódios de cheia). Mais recentemente, foi reconhecida a necessidade de melhorar a conciliação destas ações com a manutenção de atividades económicas, pelo que foram introduzidos no conceito de restauro os serviços fornecidos pelo ecossistema, quer regulatórios (de cariz ambiental), quer de aprovisionamento (numa perspetiva antropocêntrica; Figura 15.1).

A monitorização é uma componente essencial das ações de restauro ou de reabilitação (Figura 15.1). Resultados mensuráveis, obtidos a partir de campanhas de amostragem de indicadores tais como os elementos de qualidade biológica (Capítulo 14), e os elementos de 
suporte físico-químicos ou hidromorfológicos ${ }^{10}$ permitem avaliar (i) a evolução das medidas implementadas e (ii) se os objetivos globais da ação foram atingidos. O prazo de qualquer programa de monitorização deve ser suficientemente longo para poder detetar alterações mensuráveis nos indicadores, em particular nos elementos biológicos, que resultam das medidas de restauro. Infelizmente, a maioria dos programas de restauro não implementam programas de monitorização pós-projeto, resultando numa perda de informação importante sobre o efeito das medidas sobre os elementos abióticos e bióticos do meio fluvial ${ }^{11}$.

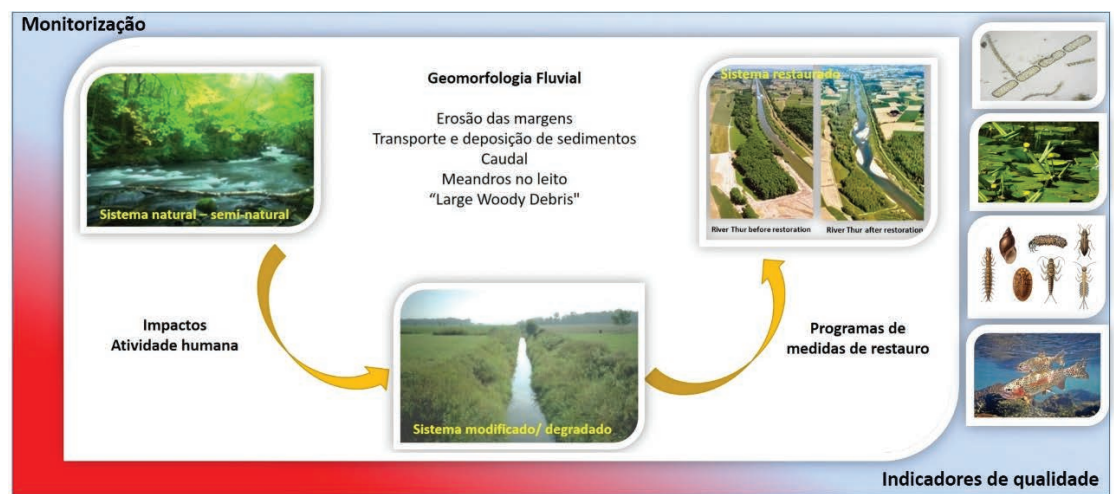

Figura 15.1. Os programas de restauro fluvial pretendem reestabelecer processos naturais hidrológicos e morfológicos encontrados em sistemas não perturbados, junto com a minimização de impactos de origem humana. Os elementos de qualidade biológica - os bioindicadores - são utilizados para monitorizar e avaliar a eficácia das medidas implementadas.

\section{Abordagens, tipologias e formas de intervenção}

As medidas de restauro e de requalificação, como já foi referido, pretendem restabelecer padrões de processos naturais e dinâmicos que contribuam para um maior grau de funcionalidade, complexidade, diversidade e resiliência do meio fluvial. Resultam no aumento do aprovisionamento de um leque de serviços de ecossistema 
importantes para o bem-estar humano ${ }^{12}$. Diferenciam-se, contudo, no grau de recuperação da estrutura e funcionalidade do sistema afetado (Figura 15.2).

As ações de restauro pretendem atingir um estado original não perturbado - as condições de referência - determinado através de dados históricos. Existe uma gama alargada de ações de reabilitação fluvial que, muitas vezes, complementam as obras de engenharia civil e sanitária. Conferem algum retorno aos aspetos de funcionalidade fluvial mas sem o objetivo de atingir um estado "original" ou de referência (Figura 15.2). Medidas de requalificação ou reabilitação podem contribuir para minimizar o impacto visual das infraestruturas cinzentas (p. ex., margens artificializadas), melhorar a qualidade da água, diminuir o risco de cheias ou de erosão ou apostar na recuperação de habitats para espécies alvo na zona de intervenção. São muitas vezes implementadas em áreas altamente intervencionadas pela atividade humana (p.ex., o meio urbano) onde existem infraestruturas quase impossíveis de retirar sem prejuízo ou com custos bastante elevados.

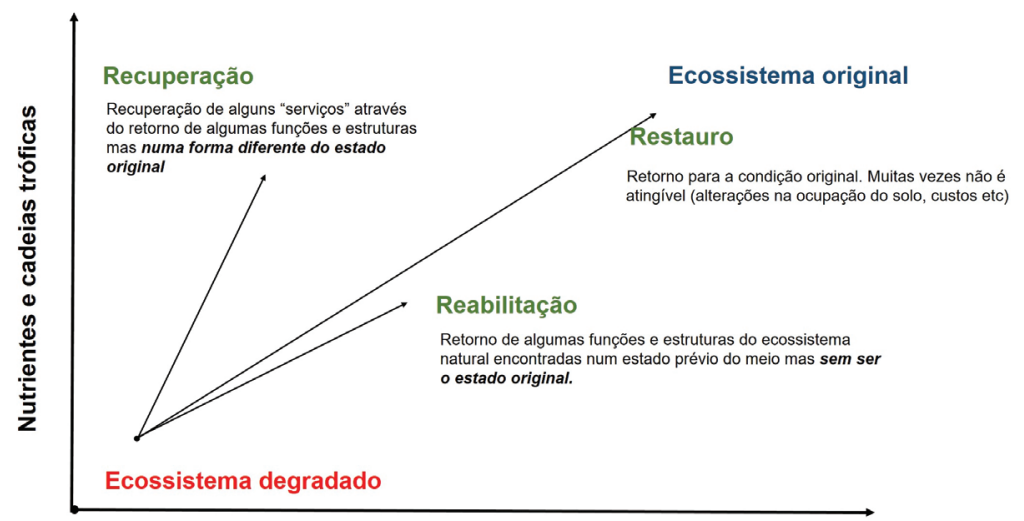

Diversidade biológica e hidromorfológica

Figura 15.2. A recuperação, o restauro e a reabilitação fluvial apostam em formas diferentes sobre a estrutura e função do ecossistema para atingirem objetivos distintos (adaptado de Bradshaw ${ }^{13}$ ). 


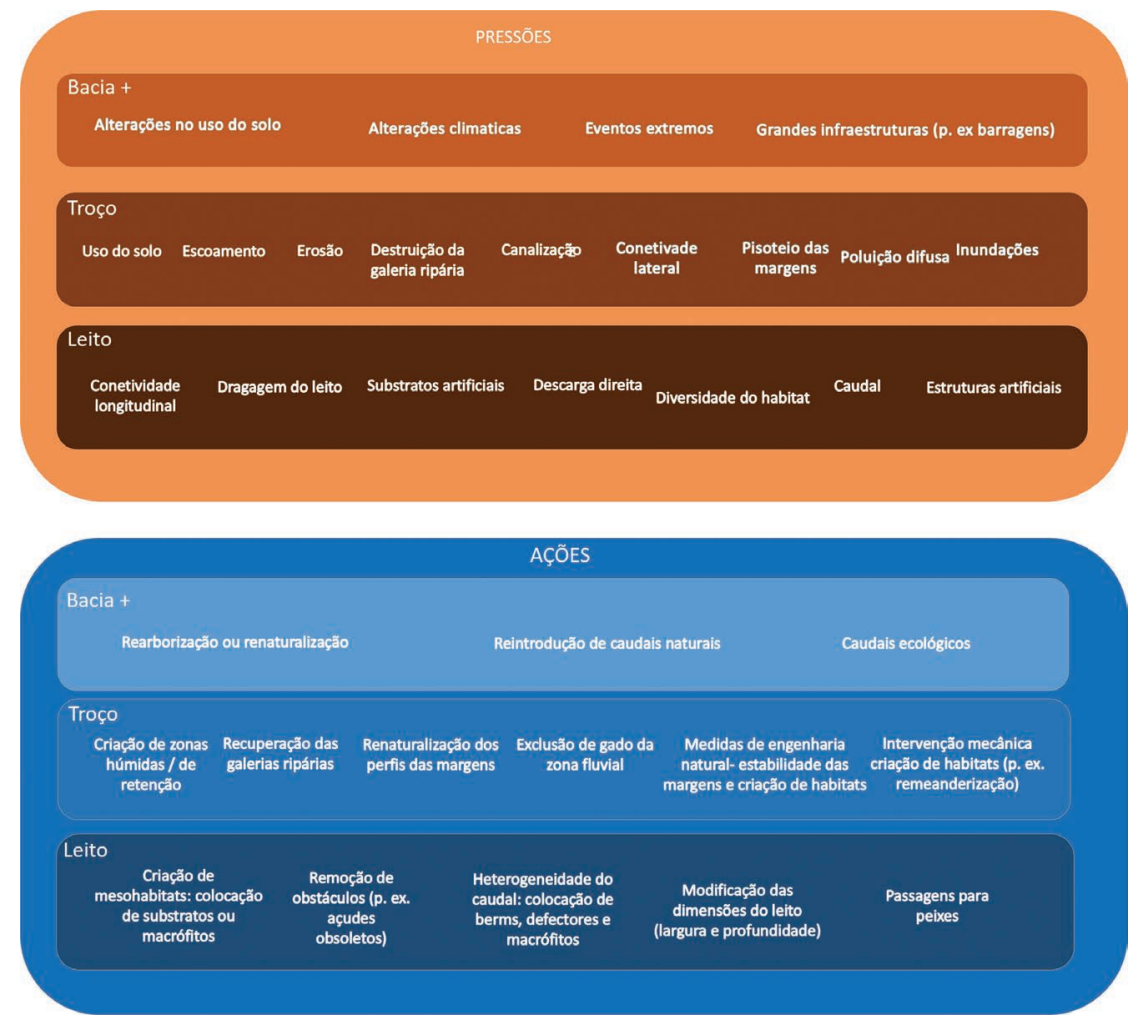

Figura 15.3. Alguns exemplos das pressões (caixa laranja) sobre os sistemas fluviais e das ações de restauro (caixa azul) que podem ser utilizadas em programas para diminuir o efeito dos impactos. As pressões e as ações foram ambas distribuídas por níveis espaciais que devem ser considerados no desenvolvimento de atividades de restauro. A seleção e implementação de conjuntos de ações baseiam-se nos objetivos pretendidos no âmbito do projeto de restauro fluvial bem como nos recursos disponíveis.

Um projeto de restauro ou de reabilitação bem sucedido assenta no conhecimento socioecológico da área de intervenção e numa abordagem multidisciplinar, mas flexível, dada a natureza dinâmica dos sistemas fluviais. É imprescindível inventariar todas as pressões, nos seus vários níveis espaciais (bacia, troço e leito), exercidas sobre a massa de água (Figura 15.3). O estado de um troço fluvial degradado resulta da atuação integrada e simultânea das pressões. Assim, 
é lógico que a sua recuperação requeira igualmente uma resposta integrada, baseada na coordenação de conjuntos de ações e técnicas de restauro, implementadas a diferentes níveis e escalas espaciais e temporais de modo a (i) permitir controlar a influência dos elementos de pressão que foram identificados e (ii) apoiar a evolução do ecossistema para o estado natural ${ }^{10}$. Por exemplo, os problemas de erosão, descargas pontuais de poluição e a presença de espécies invasoras (Figura 15.4) implicam a implementação de várias medidas de restauro, desde o controlo de invasoras (p.ex., programas de erradicação), a mitigação da poluição (p.ex., zona húmidas a atuarem como filtros biológicos) e a reconstrução da galeria ripária (p.ex., programas de rearborização, exclusão de gado, renaturalização das margens) que desempenham múltiplas funções na área de intervenção.

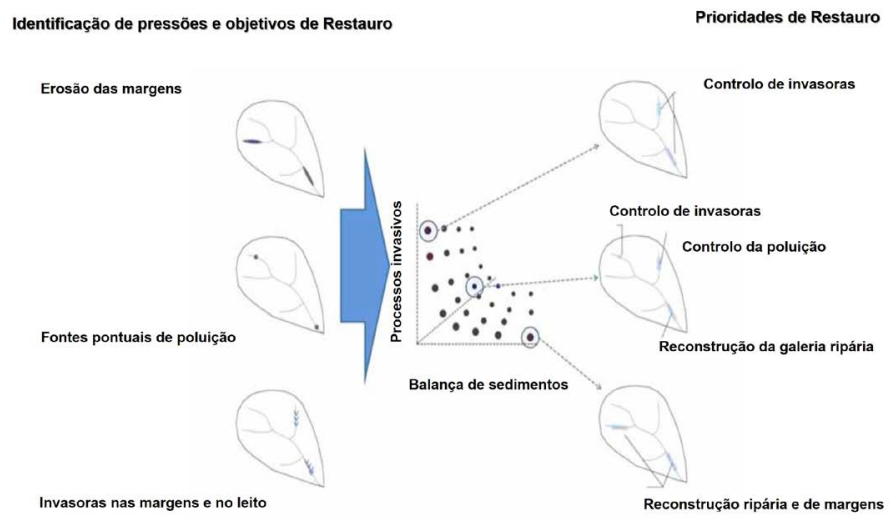

Figura 15.4. Integração de diferentes objetivos de intervenção em função das pressões e das prioridades e da probabilidade de eficácia ${ }^{14}$.

Perante um tão grande número de objetivos e técnicas de restauro fluvial seria impossível uma abordagem completa num único capítulo. Nesse sentido daremos relevância a aspetos relativamente inovadores em termos de restauro, tais como a noção de território fluvial, a criação de matrizes de infraestruturas verdes, as fases que constituem um projeto de restauro ecológico e a avaliação da sua eficácia. 
Descrevemos também um exemplo de um projeto de reabilitação de um curso de água, o rio Odelouca, situado na região do Algarve.

\section{Território fluvial}

O restauro fluvial pretende reestabelecer a conetividade, i.e., devolver ao rio o espaço na bacia que lhe foi usurpado pela atividade humana. Este espaço é o território fluvial, sendo o terreno e respetiva paisagem definidos pela rede fluvial. É uma faixa ativa do ponto de vista geomorfológico e ambiental, desde o leito menor até ao leito de cheia normal, sem quaisquer constrangimentos físicos artificiais. O território fluvial compreende: (i) os diferentes percursos do leito, que podem ser determinados por registos cartográficos antigos; (ii) meandros abandonados ou braços mortos que não estão ligados ao canal principal; (iii) faixas terrestres suscetíveis de serem erodidas nas próximas décadas pela dinâmica do canal fluvial a partir da determinação da evolução geomorfológica; e (iv) todas as áreas inundadas pelo rio nos últimos 5-10 anos.

O território fluvial deve ser delimitado pela evolução geomorfológica, ecológica e histórica, sem limites permanentes ${ }^{15}$, e com suficiente largura e continuidade de modo a potenciar a diversidade ecológica segundo a Diretiva Habitats ${ }^{4}$, o bom estado ecológico, de acordo com a DQA ${ }^{5}$, e a atenuação natural dos episódios de cheias respeitando a Diretiva de Inundações ${ }^{6}$.

O território fluvial e as estruturas habitacionais a ele associadas estão também profundamente dependentes das alterações do regime de caudais e da retenção de água a montante por barragens, que afetam também a dinâmica de transporte de sedimentos, alterando os perfis transversais e longitudinais (Figura 15.5). O devido reconhecimento e recuperação do território fluvial implica assim, a eliminação de diques e a renaturalização de troços retificados 
e canalizados. Obriga ainda a compromissos sociais importantes, resultantes do acordo entre os vários stakeholders, uma vez que o uso da terra está dedicado a outros fins (p.ex., agricultura, edificações). Instrumentos administrativos possíveis passam pela aquisição ou expropriação dos terrenos fluviais, ou desde logo por impedir construções, em linha com a Diretiva de Inundações.

A agricultura intensiva e o desenvolvimento urbano e industrial constituem os maiores constrangimentos à proteção ou recuperação do território fluvial. É preciso ter em conta que as atividades económicas relacionadas diretamente e indiretamente com estes setores sofrerão efeitos dramáticos a longo prazo se o território fluvial não for respeitado e sujeito a ordenamento adequado e sustentável. Os fenómenos hidrológicos extremos, associados com as alterações climáticas terão então elevados custos económicos (com a perda de solo e destruição de habitações e infraestruturas), ambientais e humanos.
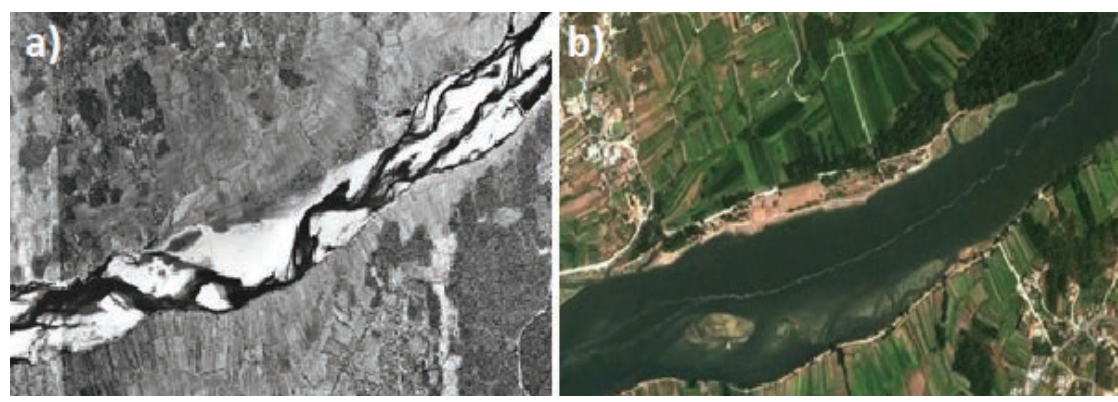

Figura 15.5. Variação da geomorfologia fluvial do setor terminal do rio Lima entre 1965 (a) e 2010 (b) como resultado da extração de inertes, evidenciando as variações estruturais e na dimensão do território fluvial.

\section{Infraestruturas verdes}

As infraestruturas verdes (IF-V; Tabela 15.1) podem ser definidas como uma rede interconectada de espaços verdes (sistemas terrestres) 
e azuis (sistemas aquáticos) de modo a conservarem as funções e valores dos ecossistemas e fornecerem múltiplos benefícios para as populações. As IF-V são redes estrategicamente planeadas entre espaços urbanos e naturais para proporcionar benefícios ecológicos, económicos e sociais, através de soluções naturais ${ }^{16}$.

Tabela 15.1.

Benefícios múltiplos de algumas infraestruturas verdes (IF-V) vocacionadas para zonas urbanas em várias características do ciclo hidrológico ${ }^{17}$.

\begin{tabular}{|l|l|l|l|l|l|}
\hline Benefícios IF-V & $\begin{array}{l}\text { Banda } \\
\text { ripária }\end{array}$ & $\begin{array}{l}\text { Canais } \\
\text { vegetados }\end{array}$ & $\begin{array}{l}\text { Bacia de } \\
\text { infiltração }\end{array}$ & $\begin{array}{l}\text { Jardim de } \\
\text { chuva }\end{array}$ & $\begin{array}{l}\text { Zona } \\
\text { húmida }\end{array}$ \\
\hline Controlo de cheias & & & & & \\
\hline Biodiversidade & & & & & \\
\hline Valor estético & & & & & \\
\hline Adaptabilidade & & & & & \\
\hline Depuração & & & & & \\
\hline Retenção & & & & & \\
\hline Infiltração & & & & & \\
\hline Escoamento & & & & & \\
\hline Filtração & & & & & \\
\hline
\end{tabular}

O documento Green Infrastructure (GI) - Enhancing Europe's Natural Capital publicado pela Comissão Europeia em 2013 promove a criação e gestão das IF-V para garantir o fornecimento sustentável de múltiplos serviços de ecossistema. As IF-V permitem o fornecimento sustentável de um leque notável de serviços, tais como serviços de suporte (p.ex., formação do solo, produção de oxigénio, reciclagem de nutrientes), serviços de aprovisionamento (p.ex., alimentos, água, madeira, recursos genéticos), serviços de regulação (p.ex., regulação climática, regulação e purificação) e serviços culturais (p.ex., ecoturismo e recreação, estético e inspiração, educacional, herança cultural).

As IF-V melhoram o grau da conetividade entre habitats fragmentados, propiciando uma maior biodiversidade, diminuição no 
efeito de episódios de cheia, aumento na taxa de recarga das águas subterrâneas e no sequestro de carbono e melhoria na qualidade de água. As IF-V também são importantes estruturas de lazer ligadas ao apoio a serviços de ecossistemas culturais, tais como a educação ambiental, percursos pedestres, ciclovias, postos de observação de aves e pesca desportiva.

Muitas IF-V são também consideradas Medidas de Retenção Natural de Água (MRNA). As MRNA aumentam a área das zonas de infiltração de água (contribuindo assim para a recarga das águas subterrâneas), diminuindo o escoamento superficial e, consequentemente, a ocorrência de inundações e as alterações hidrológicas impostas pela regularização e alterações no uso do solo. Em zonas urbanas, estas medidas são particularmente interessantes pelo valor acrescido que trazem (Figura 15.6) em termos de requalificação ambiental.

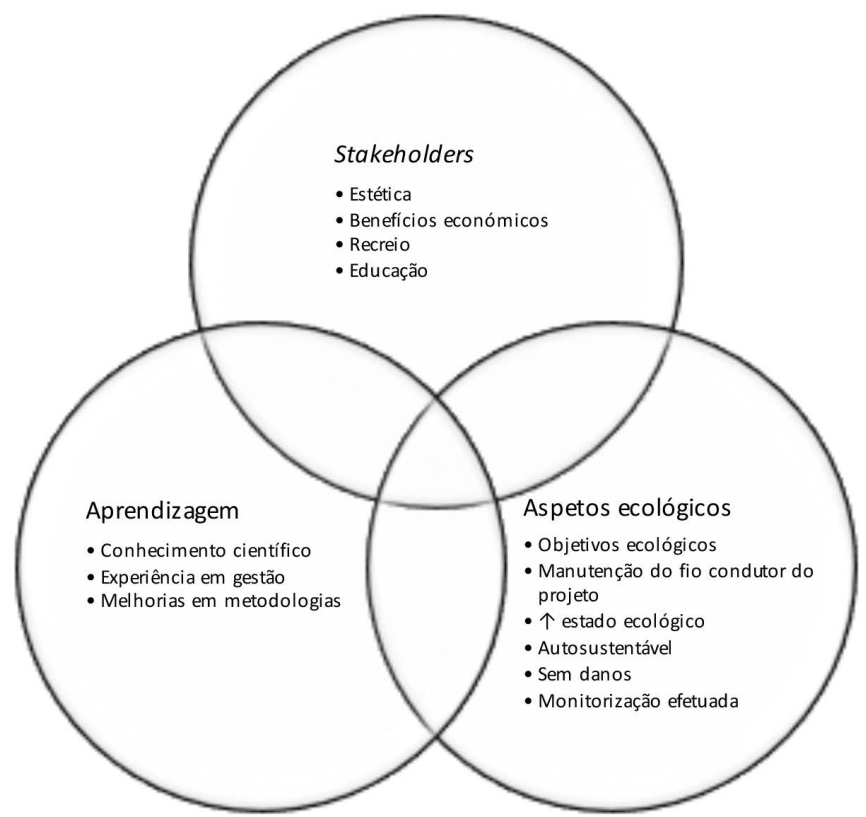

Figura 15.6. Um projeto de restauro fluvial bem sucedido deve ir ao encontro de 3 conceitos de êxito, baseado nos benefícios para os stakeholders, nos aspetos ecológicos e nos avanços em termos de aprendizagem. 


\section{Planeamento do restauro e conceitos chave}

Um projeto de restauro fluvial deve trazer mais-valias para áreas distintas, mas essenciais na sua implementação (Figura 15.7). O êxito para os stakeholders deve refletir a satisfação socioeconómica com os resultados obtidos, enquanto o êxito em termos de aprendizagem é suportado por avanços no conhecimento científico e nas práticas de gestão durante a sua execução que irão beneficiar futuras ações de restauro. O êxito em termos ecológicos significa uma melhoria da biodiversidade e da qualidade dos habitats do troço sujeito a intervenção e que os objetivos de renaturalização do troço foram alcançados $^{11}$. Um projeto de restauro deve obedecer a uma sequência de trabalhos e contar com a contribuição de participantes oriundos de vários setores. O projeto deve ser tecnicamente adequado, aceitável do ponto de vista socioambiental e comportável para as condições financeiras existentes (Figura 15.7).

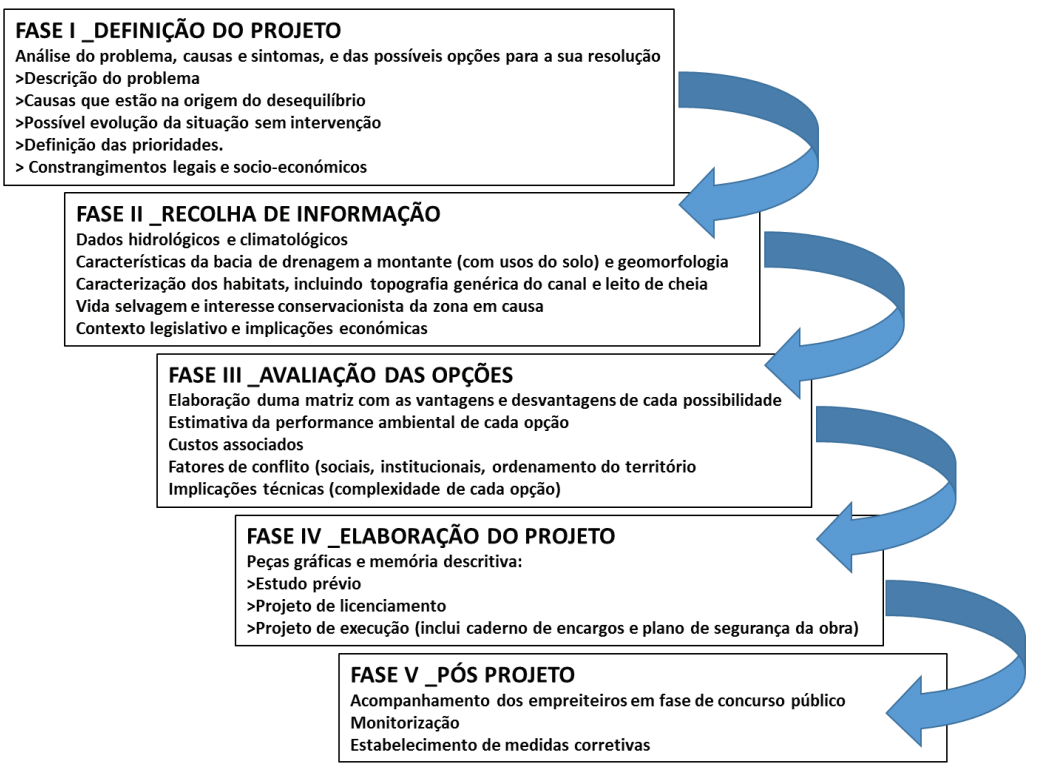

Figura 15.7. Conjunto de procedimentos e informações para a realização e seguimento de um projeto de restauro. 
Qualquer projeto de restauro lida com componentes bióticas e abióticas. A evolução do sistema fluvial sujeito a restauro age de forma estatisticamente preditiva de acordo com o desenrolar de processos hidromorfológicos associados com a tipologia do rio sujeito à intervenção. Todavia, existe um dado grau de incerteza associado com fenómenos físicos extremos, tais como episódios de cheia e seca, sendo necessária uma abordagem de gestão adaptativa. Esta abordagem contempla possíveis alterações ou modificações, ao longo e depois da implementação do projeto, com o fim de corrigir ou complementar as medidas implementadas. A linha condutora desta gestão adaptativa provém dos resultados obtidos a partir de campanhas de monitorização.

A Tabela 15.2 sumariza as linhas gerais que devem ser usadas para avaliar o sucesso do restauro com base na análise de 5 critérios, devendo os procedimentos procurarem diminuir a complexidade e os custos inerentes da avaliação ${ }^{11}$.

Tabela 15.2.

Critérios para avaliar o sucesso de restauro fluvial ${ }^{11}$.

\begin{tabular}{|c|c|c|}
\hline Critério & Indicadores & Processos/Metas \\
\hline $\begin{array}{l}\text { Conhecimento } \\
\text { do estado di- } \\
\text { nâmico do rio }\end{array}$ & $\begin{array}{l}\text { Indicadores bióticos e abióticos } \\
\text { que permitam analisar a capa- } \\
\text { cidade do sistema dentro de } \\
\text { limites locais e da bacia hidro- } \\
\text { gráfica. Procurar avaliar quanto } \\
\text { do restauro efetuado ao nível } \\
\text { do troço local pode ter reper- } \\
\text { cussões a nível de bacia. }\end{array}$ & $\begin{array}{l}\text { Plano de reabilitação que defina } \\
\text { os resultados a esperar no troço } \\
\text { intervencionado, p.ex., simulação } \\
\text { de imagens que mostrem a nova } \\
\text { reconfiguração do rio e habitats; } \\
\text { objetivos específicos a atingir } \\
\text { (p.ex., diminuir a eutrofização, } \\
\text { aumentar a densidade de uma } \\
\text { população-alvo). }\end{array}$ \\
\hline $\begin{array}{l}\text { Melhoria dos } \\
\text { ecossistemas }\end{array}$ & $\begin{array}{l}\text { Indicadores de integridade eco- } \\
\text { lógica selecionados com base } \\
\text { nas pressões presentes. }\end{array}$ & $\begin{array}{l}\text { Melhorar a qualidade da água, } \\
\text { implementar o regime de caudais } \\
\text { próximo do natural, aumentar a } \\
\text { viabilidade de espécies nativas, } \\
\text { controlar exóticas, melhorar a } \\
\text { vegetação ripária e de habitats. }\end{array}$ \\
\hline $\begin{array}{l}\text { Aumento da } \\
\text { resiliência }\end{array}$ & $\begin{array}{l}\text { Alterações do leito e de } \\
\text { espécies-alvo face a fenómenos } \\
\text { hidrológicos extremos ou a } \\
\text { agentes de perturbação. }\end{array}$ & $\begin{array}{l}\text { O sistema deve requerer uma in- } \\
\text { tervenção mínima pós-intervenção } \\
\text { tendo a capacidade de recuperar } \\
\text { de perturbações naturais e de in- } \\
\text { fluências antropogénicas normais. }\end{array}$ \\
\hline
\end{tabular}




\begin{tabular}{lll}
\hline Critério & Indicadores & Processos/Metas \\
\hline $\begin{array}{l}\text { Impactos ne- } \\
\text { gativos asso- } \\
\text { ciados com } \\
\text { as ações de } \\
\text { restauro são } \\
\text { temporários }\end{array}$ & $\begin{array}{l}\text { Avaliação da sensibilidade da } \\
\text { paisagem às medidas introduzi- } \\
\text { das. Análise de indicadores de } \\
\text { qualidade visual e da capacida- } \\
\text { de de absorção visual. }\end{array}$ & $\begin{array}{l}\text { Os impactos da intervenção não } \\
\text { devem causar impactos negativos } \\
\text { irreversíveis. Devem permitir a } \\
\text { recuperação da vegetação natural } \\
\text { após as obras, eliminar substratos } \\
\text { finos e minimizar o impacto visual } \\
\text { das estruturas introduzidas. }\end{array}$ \\
$\begin{array}{l}\text { Avaliação do } \\
\text { estado ecoló- } \\
\text { gico }\end{array}$ & $\begin{array}{l}\text { Avaliação através do uso de } \\
\text { indicadores que permitam com- } \\
\text { parar a situação inicial com a } \\
\text { situação pós intervenção. Se- } \\
\text { gundo a DQA devem ser indica- } \\
\text { dores biológicos e de suporte. }\end{array}$ & $\begin{array}{l}\text { Os objetivos do projeto devem ser } \\
\text { claramente definidos, procurando- } \\
\text {-se recolone informação sobre a } \\
\text { a mestado ecológico e se } \\
\text { tivos a atingir. }\end{array}$ \\
\hline
\end{tabular}

\section{Caso de estudo de requalificação fluvial: o rio Odelouca}

A bacia do rio Odelouca, situada na região do Algarve, é de alto valor conservacionista devido à presença de galerias ripárias intactas e floristicamente diversas situadas nalguns troços do rio (parcialmente submersos após a conclusão da barragem de Odelouca) e pela presença de espécies altamente ameaçadas tais como espécies endémicas de peixes (Iberochondrostoma almacai e Squalius aradensis), o lince Ibérico (Lynx pardinus) ${ }^{10,18-20}$ e a águia de Bonelli (Hieraaetus fasciatus). Parte do rio Odelouca situa-se na Rede Natura 2000 (Monchique - PTCON0037). O rio Odelouca é um sistema fluvial tipicamente mediterrânico, caracterizado por um regime hidrológico altamente sazonal, tendo uma época estival sem pluviosidade e fortes episódios de pluviosidade durante o Inverno ${ }^{10,18}$.

Com o fim de melhorar o abastecimento de água, na região do Algarve, foi construída (em 2010) a barragem de Odelouca, um processo altamente contestado. Inicialmente foi embargado devido aos protestos apresentados à Comissão Europeia quanto à violação do valor de conservação intrínseco da área. Em 2005, uma decisão ministerial veio reativar e finalizar a sua construção sob a condição de 
implementar um extenso programa de medidas de mitigação, medidas compensatórias e monitorização, de forma a compensar os impactos da construção da barragem e da perda de habitats prioritários.

Uma das muitas medidas foi a Valorização e Requalificação das Galerias Ribeirinhas na Área do Empreendimento de Odelouca. Antes da construção da barragem, as galerias ripárias da bacia de Odelouca com maior extensão e diversidade florística (Fraxinus angustifolia, Salix atrocinerea, Salix australis, Alnus glutinosa, Nerian oleander, Tamarix africana e Erica lusitanicum) situavam-se precisamente na futura zona de inundação. Em 2005 iniciou-se um programa integrado no âmbito desta medida para recuperar, requalificar e valorizar as galerias ripárias afetadas pela construção da barragem. As ações incluíram inicialmente uma caracterização de toda a bacia, com o levantamento dos habitats de maior valor conservacionista e dos impactos existentes, de modo a definirem-se os troços prioritários de atuação. Este foi um caso único em que os segmentos a reabilitar resultaram dum estudo intenso de toda a bacia (Figura 15.8). De um modo mais global as ações envolveram: (i) caracterização da composição e estrutura atualmente existentes da vegetação aquática e ripária no rio Odelouca e a avaliação de sua integridade e continuidade longitudinal; (ii) caracterização de habitats fluviais e das margens e a avaliação da qualidade e grau de perturbação humana; (iii) inventariação e caracterização das principais comunidades bióticas (avifauna, macroinvertebrados bentónicos, peixes e macrófitos), avaliação do seu potencial como indicadores de qualidade dos corredores fluviais, campanhas de amostragem efetuadas em 30 troços abarcando locais de referência (presumivelmente isentos de perturbação) e locais perturbados pelas obras, análise e seleção de bioindicadores para aplicação em programas de monitorização de medidas de requalificação e reabilitação na área de intervenção ${ }^{10,17}$; (iv) desenvolvimento de práticas de silvicultura de espécies lenhosas nativas em viveiro em colaboração com stakeholders regionais (proprietários de viveiros) para ações de 
requalificação das galerias ripárias; (v) estudo do papel funcional das comunidades ripárias na formação e estruturação de habitats e processos fluviais e aplicação deste conhecimento no desenvolvimento de medidas de reabilitação em troços selecionados; (vi) modelação hidráulica e validação de alterações abióticas e bióticas decorrentes de ações de requalificação; (vii) desenvolvimento e implementação de um programa de requalificação e medidas de reabilitação para galerias ribeirinhas de Odelouca e habitats para peixes em troços selecionados (Figura 15.9); e (viii) monitorização de medidas de requalificação e reabilitação de habitats para peixes.
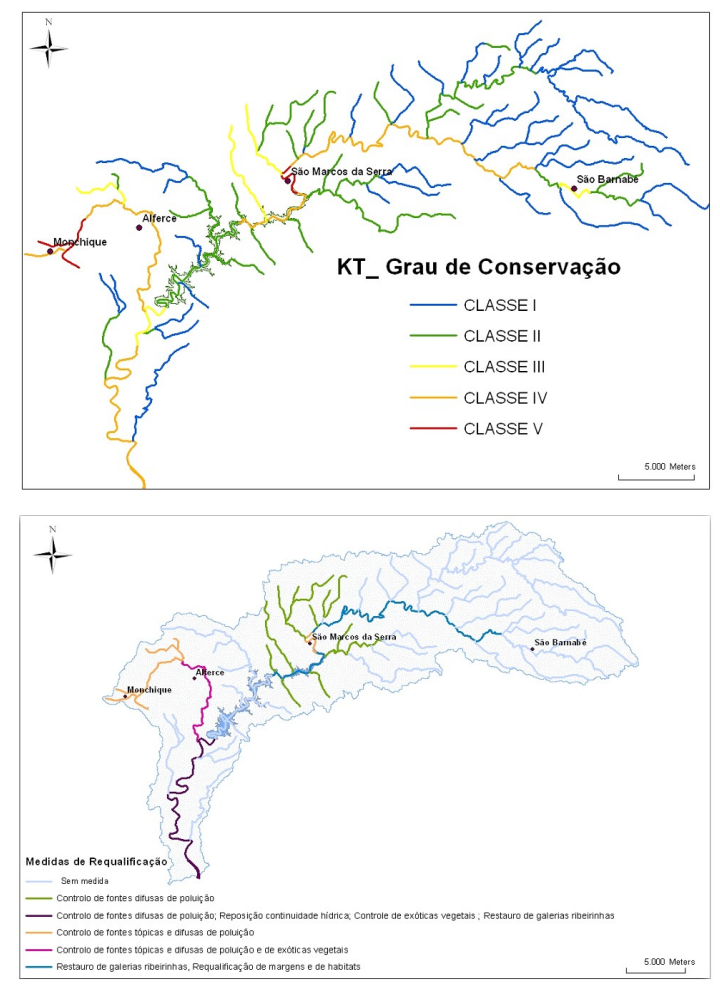

Figura 15.8. A caracterização pormenorizada da bacia do rio Odelouca, a partir de um levantamento das suas características abióticas, biológicas e das pressões, permitiu a classificação dos troços em 5 classes de acordo com o seu grau de conservação tendo as classes IV e V sido consideradas prioritárias. 

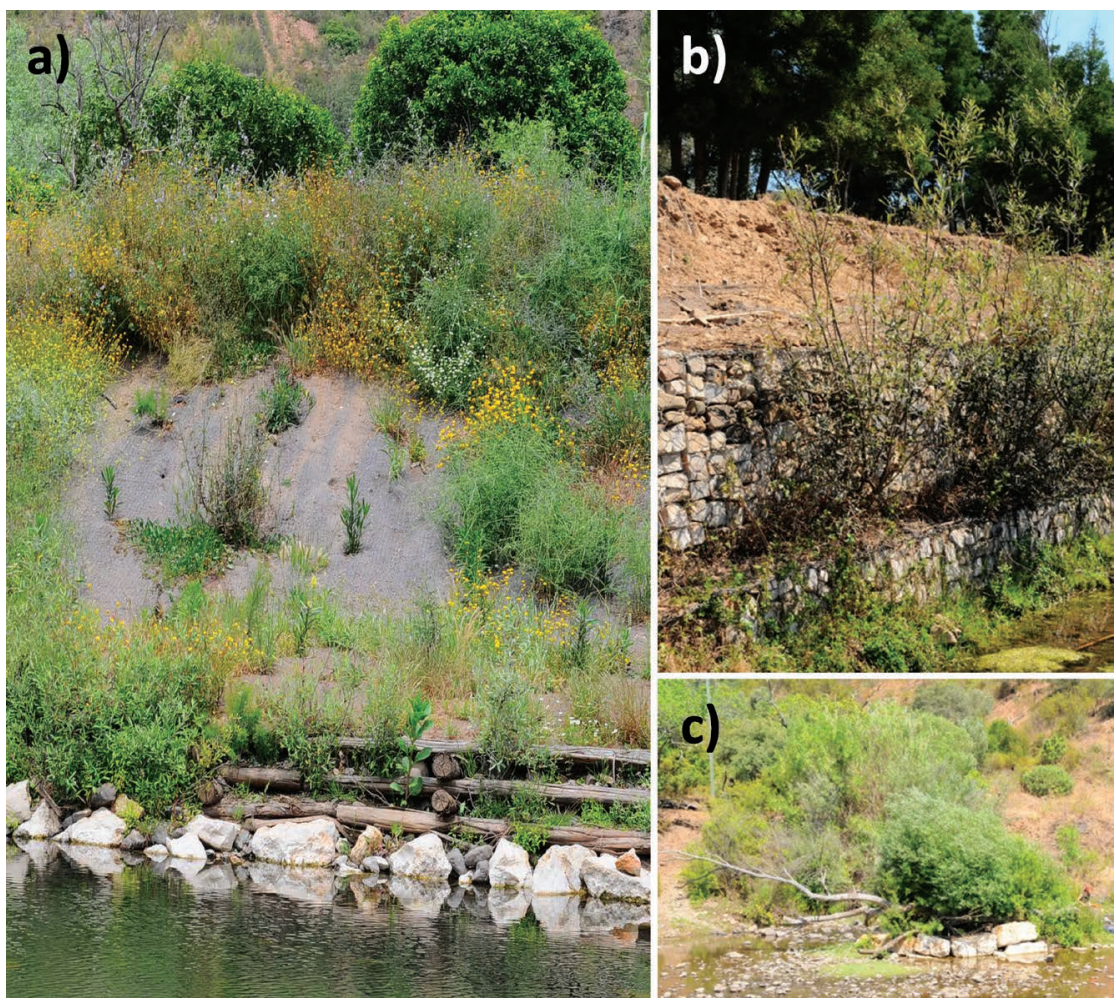

Figura 15.9. Técnicas de engenharia natural utilizadas no rio Odelouca: a) e b), remoção da vegetação infestante (canavial) e consolidação dos taludes respetivamente com caixas e enrocamentos vegetados, aplicando-se biomantas e plantações de espécies ripárias na parte superior dos taludes; c), criação de ilhas vegetadas para favorecer os ciprinídeos autóctones. Fotografias: Rui Cortes.

Debatem-se frequentemente duas correntes para o restauro ecológico9: (i) as que representam uma perspetiva ecocêntrica, de objetivos exclusivamente ambientais, considerando as atividades humanas como secundárias e devendo necessariamente sujeitar-se aos objetivos de bom funcionamento do ecossistema, e (ii) as que representam uma perspetiva antropocêntrica, considerando as atividades humanas como prioritárias, sendo o restauro efetuado com o objetivo de as proteger ou de as favorecer, embora com preocupações 
de "naturalidade". A primeira corrente seria representada pela DQA que subordina o restauro a objetivos ambientais de obtenção do "Bom Estado" do ecossistema fluvial ${ }^{21}$. A segunda corrente, que deve ser mais corretamente designada por requalificação fluvial, abarca todas as obras de engenharia civil e sanitária que permitem melhorar a qualidade da água e diminuir o risco de cheias e de erosão associada, mas também de arquitetura paisagista, engenharia natural e engenharia florestal, vocacionadas para tornar as obras hidráulicas mais amigáveis do ponto de vista ambiental, e para incrementar habitats ripários, diminuindo o carácter artificial dessas obras e potenciando a naturalização das linhas de água com reflexos no seu valor cénico.

Idealmente, restauro ecológico é a recriação de comunidades de organismos muito semelhantes aos que ocorrem naturalmente sendo uma forma de auxiliar, melhorar e estabelecer os processos hidrológicos, geomorfológicos e ecológicos numa bacia hidrográfica degradada, substituindo a perda de elementos que pertencem ao sistema natural. Tal perspetiva implica uma visão holística da bacia de drenagem e do vale e canais fluviais, incluindo as pressões e os efeitos destas integradas e atuando de forma conjunta. Igualmente implica um desígnio societal claro e a cooperação de todos os intervenientes, bem como do sistema administrativo e legislativo, de forma a concertadamente e de forma planeada serem realizadas as ações conducentes ao restauro efetivo.

\section{Referências bibliográficas}

\footnotetext{
${ }^{1}$ Postel S. \& Richter B. 2003. Rivers for life: managing water for people and nature. Vol. 20. Island Press. U.S.A., Washington, DC

${ }^{2}$ Ormerod S.J. 2004. A golden age of river restoration science? Aq. Conserv.: Mar. Freshwat. Ecosyst. 14: 543-549

${ }^{3}$ Palmer M.A., Hondula K.L. \& Koch B.J. 2014. Ecological restoration of streams and rivers: shifting strategies and shifting goals. Ann. Rev. Ecol. Evol. Syst. 45: $247-269$
} 
${ }^{4}$ Comissão Europeia. 1992. Directiva 92/43/EEC do Parlamento Europeu e do Concelho de 21 de Maio de 1992, que estabelece um quadro para a conservação dos habitats naturais e da fauna e flora silvestres. J. Ofic. Com. Europ. L206: 7-50

${ }^{5}$ Comissão Europeia. 2000. Directiva 2000/60/EC do Parlamento Europeu e do Concelho de 23 de Outubro de 2000, que estabelece um quadro de acção comunitária no domínio da política da água. J. Ofic. Com. Europeias L327: 1-72

${ }^{6}$ Comissão Europeia. 2007. Directiva 2007/60/EC do Parlamento Europeu e do Concelho de 23 October 2007, que estabelece um quadro para a avaliação e gestão dos riscos de cheias. J. Ofic. Com. Europeias L288: 27-34

${ }^{7}$ Maller C., Townsend M., Pryor A., Brown P. \& St Leger L. 2006. Healthy nature healthy people: 'contact with nature' as an upstream health promotion intervention for populations. Health Promot. Int. 21: 45-54

${ }^{8}$ Wheeler B.W., Lovell R., Higgins S.L., White M.P., Alcock I., Osborne N.J., Husk K., Sabel C.E. \& Depledge M.H. 2015. Beyond greenspace: an ecological study of population general health and indicators of natural environment type and quality. Int. J. Health Geogr. 14: 1-17

${ }^{9}$ Ferreira M.T. 2012. Restauro, reabilitação e gestão fluviais. In: Camprodon J., Ferreira M. T. \& Ordeix M. (eds.) Restauro e gestão ecológica fluvial. Centre Tecnologic Forestal de Catalunya/ISA press, pp. 16-22

${ }^{10}$ Hughes S.J., Santos J., Ferreira T. \& Mendes A. 2010. Evaluating the response of biological assemblages as potential indicators for restoration measures in an intermittent mediterranean river. Environ. Manag. 46: 285-301

${ }^{11}$ Palmer M.A., Bernhardt E.S., Allan J.D., Lake P.S., Alexander G., Brooks S., Carr J., Clayton S., Dahm C.N., Follstad Shah J. \& Galat D.L. 2005. Standards for ecologically successful river restoration. J. Appl. Ecol. 42: 208-217

${ }^{12}$ MEA. 2005. Millenium Ecosystem Assessment. Ecosystems and Human Well-Being: Synthesis. I. Press. U.S.A., Washington, D.C.

${ }^{13}$ Bradshaw A.D. 1987. Restoration: an acid test for ecology. In: Jordan W.R., Gilpin M.E. \& Aber J.D. (eds.) Restoration ecology: a synthetic approach to ecological research. Cambridge University Press. U.K., Cambridge, pp. 23-30

${ }^{14}$ Camprodon J., Ferreira M.T. \& Ordeix M. (eds.). 2012. Restauro e gestão ecológica fluvial: manual de boas práticas de gestão de rios e ribeiras. Centre Tecnologic Forestal de Catalunya/ISA press.

15Ollero A. \& Elso J. 2007. The need for a "fluvial territory" or "room for the river": living with floods by acceptance of their functions. In: Baker C. \& van Eijk P. (eds.) Sustainable flood management: obstacles, challenges and solutions. Interreg IIIC Network FLAPP "Flood Awareness and Prevention Policy in border areas", pp. 59-63

${ }^{16}$ Benedict M.A. \& McMahon E.T. 2012. Green infrastructure: Inking landscapes and communities. Island Press.

${ }^{17}$ Perini K. \& Sabbion P. 2017. Front matter. In: Urban sustainability and river restoration: green and blue infrastructure. John Wiley \& Sons Ltd., pp: i-xvi

${ }^{18}$ Hughes S.J., Santos J., Ferreira M.T., Caraça R. \& Mendes A.M. 2009. Ecological assessment of an intermittent Mediterranean river using community structure and function: evaluating the role of different organism groups. Freshwat. Biol. 54: $2383-2400$ 
${ }^{19}$ Hughes S.J., Ferreira T. \& Cortes R.V. 2008. Hierarchical spatial patterns and drivers of change in benthic macroinvertebrate communities in an intermittent Mediterranean river. Aq. Conserv: Mar. Freshw. Ecosyst. 18: 742-760

${ }^{20}$ Fernandes M.R., Ferreira M.T., Hughes S., Cortes R., Santos J.M. \& Pinheiro P.J. 2007. Pré-classificação da qualidade ecológica na bacia de Odelouca e sua utilização em directrizes de restauro. Recursos Hídricos 28: 15-24

${ }^{21}$ Pollard P. \& Huxham M. 1998. The European Water Framework Directive: a new era in the management of aquatic ecosystem health? Aq. Conserv.: Mar. Freshw. Ecosyst. 8: 773-792 